\title{
Avaliação da viabilidade de sementes de café por exsudatos
}

\section{Evaluation of the coffee seeds viability by exudates}

\author{
Gustavo Hiroshi Sera ${ }^{1}$; Édison Miglioranza ${ }^{2}$; Tumoru Sera ${ }^{3}$
}

\begin{abstract}
Resumo
Existe uma grande necessidade de testes que possibilitem uma avaliação rápida e segura da qualidade das sementes. O objetivo deste trabalho foi estimar o coeficiente de correlação existente entre a germinação de sementes de café e a liberação de exsudato marrom. Utilizaram-se placas de Petri e papel-toalha umedecido onde foram colocadas as sementes. Os materiais foram obtidos de lotes de sementes com vários níveis de envelhecimento. Foi utilizado o delineamento em blocos ao acaso com 7 repetições e parcelas constituídas de 10 sementes. Obtiveram-se correlações negativas altas e significativas a 1\% entre a germinação e vigor germinativo com a liberação de exsudato marrom. As análises de variância indicaram diferenças significativas na germinação entre sementes de diferentes graus de envelhecimento em relação aos exsudatos marrons. A vantagem desta técnica é avaliar o poder germinativo em poucas horas, sem o uso de mão-de-obra especializada e equipamentos caros.
\end{abstract}

Palavras-chave: Sementes de café, germinação, viabilidade

\begin{abstract}
A quick evaluation of the germination quality of the seeds is very important for coffee growers. The aim of this research was to estimate the correlation coefficient between the germination and the liberation of brown exudates of coffee seeds with different times after preparation. Petri dishes and humid filter were used to place the seeds. The seeds were obtained from lots of seeds with several aging degrees. The experimental design used was in randomized blocks with seven replications and plots constituted by 10 seeds. High negative correlations $(\mathrm{P}=0.01)$ were obtained between the germination and germinative vigour with the liberation of brown exudates at different times. The variance analyses indicated significant differences to germination among seeds of different aging degrees at different evaluation times. The advantage of this technique is to evaluate the germinative quality in six or twelve hours, without the use of specialized labour and expensive equipments.

Key-words: Coffee seeds, germination of coffee, coffee crop
\end{abstract}

1 Engenheiro Agrônomo, Mestrando da UEL - E-mail: gustavosera@uol.com.br.

2 Professor do Departamento de Agronomia da UEL.

3 Pesquisador do IAPAR.

* Autor para correspondência.

Recebido para publicação 02/02/05 Aprovado em 08/12/05 


\section{Introdução}

Com o aumento da produção de sementes de café no Brasil, nos últimos anos, tem-se verificado a necessidade de testes que permitam uma avaliação rápida e segura da qualidade das sementes como é o caso do teste de tetrazólio (DIAS; SILVA, 1998) e do teste de condutividade elétrica (SOTO; ECHEVARRIA; RODRIGUEZ, 1995).

Para os viveiristas de mudas de café, é de suma importância um teste que possibilite uma avaliação rápida da qualidade das sementes. Isto porque a semente de café perde o poder germinativo rapidamente aos seis meses em saco de juta, com teor de umidade inicial das sementes em torno de $15 \%$ e armazenados em ambiente fresco, ao redor de $20^{\circ} \mathrm{C}$ (MATIELLO, 1991), aos nove meses acondicionadas em saco de polietileno hermeticamente fechado nessas mesmas condições (SOTO; ECHEVARRIA; RODRIGUEZ, 1995) e aos doze meses em câmara fria (em torno de $10^{\circ} \mathrm{C}$ ), segundo Bedaña (1962 apud RENA; MAESTRI, 1986).

A germinação de sementes de café é um processo bastante lento, pois Visweshwara, Kantha e Raju (1972 apud RENA; MAESTRI, 1986) relatam que entre 10 a 12 dias, em condições favoráveis, ocorre a emergência da radícula, enquanto que em outras culturas como o milho a mesma ocorre em torno de 4 dias conforme Magalhães e Durães (2003). Para a emissão do resultado oficial do percentual de germinação de um lote de sementes de café, as Regras para Análise de Sementes recomendam o período de 30 dias para a duração do teste (BRASIL, 1992).

Tem sido observado através de testes de condutividade elétrica que grãos de café defeituosos (pretos, verdes, ardidos e brocados) apresentam maior dano ou degradação do sistema de membranas, o que ocasiona uma maior lixiviação de íons (PRETE et al., 2000a; PRETE; SERA; FONSECA, 2000b). Neste sentido, foi observado que sementes de café de qualidades inferiores exsudam substâncias de coloração marrom, em diferentes intensidades, ao serem embebidas em água e colocadas sobre papel em placa de Petri.
Apesar dos testes de tetrazólio e de condutividade elétrica serem seguros e relativamente rápidos, necessitando em torno de 40 horas (DIAS; SILVA, 1998) e 8 horas (SOTO; ECHEVARRIA; RODRIGUEZ, 1995), respectivamente, estes necessitam de equipamentos e de mão-de-obra especializada para serem realizados.

Assim, o objetivo do presente trabalho foi avaliar a correlação entre a germinação de sementes de café avaliadas aos 15 dias e o exsudato marrom que a semente libera entre 6 e 60 horas visando encontrar um método de avaliação da viabilidade de sementes de café com baixo custo e em pouco tempo.

\section{Material e Métodos}

O experimento foi realizado em Londrina, em condições ambientais de laboratório, na altitude de $585 \mathrm{~m}$, umidade relativa do ar de $71,5 \%$, a temperatura média de $17^{\circ} \mathrm{C}$ e sem incidência direta de luz.

O experimento foi instalado em junho de 2000 no delineamento em blocos ao acaso com sete repetições e parcelas constituídas de dez sementes da cultivar IAPAR-59. Cada parcela foi representada por uma placa de Petri com $90 \mathrm{~mm}$ de diâmetro por $15 \mathrm{~mm}$ de altura. Os quatro tratamentos avaliados foram constituídos de sementes colhidas em agosto de 1998, junho de 1999 (dois meses fora da câmara fria), junho de 1999 e maio de 2000. Todos os tratamentos, após colhidos e processados, foram armazenados em sacos de juta, na câmara fria (em torno de $10^{\circ} \mathrm{C}$ ) e com umidade inicial das sementes em torno de $15 \%$. Um dos tratamentos colhidos em junho de 1999 permaneceu dois meses fora da câmara fria antes do início do experimento.

Nas placas de Petri foi colocado papel-toalha branco, mantido levemente umedecido, para que o exsudato marrom liberado pelas sementes não se misturasse com o de outras. Retirou-se manualmente o pergaminho e em seguida as sementes foram imersas em água por 5 minutos e após isso, foi removido a película prateada pois esta pode liberar 
substâncias de coloração amarelada que se confundem com o exsudato marrom. A remoção da película foi realizada esfregando, levemente, as sementes com os dedos para evitar danos no embrião. As sementes foram colocadas sobre o papel e a placa fechada para manutenção da umidade.

Avaliaram-se a exsudação marrom de cada semente atribuindo-se nota 1 para ausência de exsudato e nota 2 para presença de exsudato, nos períodos de $6 \mathrm{hs}, 12 \mathrm{hs}, 24 \mathrm{hs}, 60 \mathrm{hs}$ e 15 dias após o início do experimento. Nas primeiras horas (6 12hs), a exsudação é visualizada no papel toalha levantando-se as sementes para observar as exsudações.

Após 15 dias do início do experimento foi avaliada a qualidade das sementes pelo vigor germinativo e porcentagem de germinação. Como padrão comparativo de sementes de boa qualidade foi usado o tratamento colhido em maio de 2000 e como padrão de baixo potencial de germinação foram usadas as sementes colhidas em agosto de 1998. O vigor germinativo foi avaliado por notas subjetivas de 1 a 4, onde: nota 1 = não germinação, nota 2 = vigor baixo com lenta emissão de radícula ainda dentro do endosperma, nota 3 = vigor médio com radícula em início de emissão e nota 4 = vigor alto com radícula emitida. A germinação foi avaliada atribuindo-se nota
1 para não germinação e nota 2 para sementes em germinação com emissão de radículas.

Utilizou-se a análise de variância ao nível de média de parcelas e realizado o teste Tukey para comparar as médias. Além disso, foram estimadas as correlações entre as avaliações de exsudatos marrons nos diferentes tempos de embebição com o vigor germinativo e germinação avaliados 15 dias após o início do experimento.

\section{Resultados e Discussão}

Os coeficientes de variação das avaliações de exudações às $6 \mathrm{~h}, 12 \mathrm{~h}, 24 \mathrm{~h}, 60 \mathrm{~h}$ e 15 dias e de germinação e vigor germinativo aos 15 dias foram, respectivamente, de $9,9 \%, 7,1 \%, 6,9 \%, 6,7 \%, 6,8 \%$, $16 \%$ e 7,7\%, indicando boa precisão experimental. Pela análise de variância verificou-se significância a $1 \%$ pelo teste $\mathrm{F}$ em todas as avaliações.

Na Tabela 1 é apresentada as notas obtidas nas avaliações da germinação e vigor germinativo aos 15 dias, onde é possível observar que as sementes de maio de 2000 apresentaram maior germinação e vigor germinativo em relação aos demais tratamentos, os quais não apresentaram diferenças significativas.

Tabela 1. Notas médias das avaliações da germinação e vigor germinativo aos 15 dias em sementes de café com diferentes graus de envelhecimento.

\begin{tabular}{l|c|c}
\hline Tratamento & Germinação & Vigor Germinativo \\
\hline Maio de 2000 & $1,90 \mathrm{a}$ & $3,33 \mathrm{a}$ \\
Junho de 1999 (câmara fria) & $1,14 \mathrm{~b}$ & $1,33 \mathrm{~b}$ \\
Junho de 1999 (2 meses fora da câmara fria) & $1,09 \mathrm{~b}$ & $1,16 \mathrm{~b}$ \\
Agosto de 1998 & $1,00 \mathrm{~b}$ & $1,00 \mathrm{~b}$ \\
\hline
\end{tabular}

Médias seguidas pela mesma letra na coluna não diferem entre si pelo teste de Tukey a $1 \%$ de probabilidade. 
Na Tabela 2 está demonstrando que as sementes de maio de 2000 quando expostas aos períodos de 6 hs, $12 \mathrm{hs}$, $24 \mathrm{hs}, 60 \mathrm{hs}$ e 15 dias, sempre apresentaram menos exsudatos marrons em relação ao das sementes utilizadas nos outros tratamentos. Nos períodos de $6 \mathrm{hs}, 12 \mathrm{hs}, 24 \mathrm{hs}, 60 \mathrm{hs}$ e 15 dias, as sementes de agosto de 1998 e junho de 1999 (2 meses fora da câmara fria) não apresentaram diferenças significativas entre eles, o mesmo ocorrendo entre as sementes de junho de 1999 (câmara fria) e junho de 1999 (2 meses fora da câmara fria). As sementes de junho de 1999 (câmara fria) e agosto de 1998 apresentaram diferenças significativas.

Tabela 2. Notas médias das avaliações de exsudações em diferentes intervalos de tempo, após as sementes, com diferentes graus de envelhecimento, serem colocadas na placa de Petri.

\begin{tabular}{c|c|c|c|c|c}
\hline Tratamento & 6hs & 12hs & 24hs & 60hs & 15 dias \\
\hline Maio de 2000 & $1,13 \mathrm{a}$ & $1,14 \mathrm{a}$ & $1,14 \mathrm{a}$ & $1,16 \mathrm{a}$ & $1,16 \mathrm{a}$ \\
Junho de 1999 (câmara fria) & $1,63 \mathrm{~b}$ & $1,70 \mathrm{~b}$ & $1,73 \mathrm{~b}$ & $1,74 \mathrm{~b}$ & $1,74 \mathrm{~b}$ \\
Junho de 1999 (fora da câmara) & $1,79 \mathrm{~b}$ & $1,83 \mathrm{bc}$ & $1,83 \mathrm{bc}$ & $1,86 \mathrm{bc}$ & $1,86 \mathrm{bc}$ \\
Agosto de 1998 & $1,84 \mathrm{~b}$ & $1,91 \mathrm{c}$ & $1,94 \mathrm{c}$ & $1,94 \mathrm{c}$ & $1,96 \mathrm{c}$ \\
\hline
\end{tabular}

Médias seguidas pela mesma letra na coluna não diferem entre si pelo teste de Tukey a 1\% de probabilidade.

Assim, pelos resultados apresentados na Tabela 1 e na Tabela 2 se pode concluir que houve diferença estatisticamente significativa entre as sementes novas e as mais velhas nas avaliações da germinação e vigor germinativo aos 15 dias e nas avaliações da exsudação marrom desde apenas 6 horas após o início do experimento.
Obtiveram-se correlações negativas e significativas a $1 \%$ entre a germinação e o vigor germinativo avaliados aos 15 dias com as avaliações de exsudatos marrons liberados das sementes avaliadas às $6 \mathrm{~h}, 12 \mathrm{~h}, 24 \mathrm{~h}, 60 \mathrm{~h}$ e 15 dias (Tabela 3 ).

Tabela 3. Correlação simples por sementes de café entre germinação e vigor germinativo avaliados os 15 dias e a exsudação marrom, avaliadas às $6 \mathrm{~h}, 12 \mathrm{~h}, 24 \mathrm{~h}, 60 \mathrm{~h}$ e 15 dias.

\begin{tabular}{ccc}
\hline Períodos & Germinação (15 dias) & Vigor germinativo (15 dias) \\
\hline 6 horas & $-0,6812637^{* *}$ & $-0,564916825^{* *}$ \\
12 horas & $-0,7646938^{* *}$ & $-0,637056528^{* *}$ \\
24 horas & $-0,7777149^{* *}$ & $-0,649222113^{* *}$ \\
60 horas & $-0,8187790^{* *}$ & $-0,680857874^{* *}$ \\
15 dias & $-0,8259400^{* *}$ & $-0,687491307^{* *}$ \\
\hline
\end{tabular}

A exsudação marrom avaliada aos 15 dias apresentou correlação negativa alta e significativa a $1 \%$ de probabilidade $\mathrm{r}=-0,83^{* *}$ com a germinação. Esta correlação é alta também às 60 horas $r=-$ $0,82^{* *}$, podendo antecipar a avaliação. Com apenas 24 ou 12 horas também é alta a correlação $r=-$ $0,78^{* *}$ e $-0,76^{* *}$, respectivamente, podendo serem usadas como indicadoras seguras do poder germinativo. Pelos resultados das avaliações realizadas com apenas 6 horas verificou-se uma correlação de $\mathrm{r}=-0,68^{* *}$, revelando portanto que mesmo no menor tempo de embebição já ocorre exsudação no substrato (Figuras 1 e 2). 

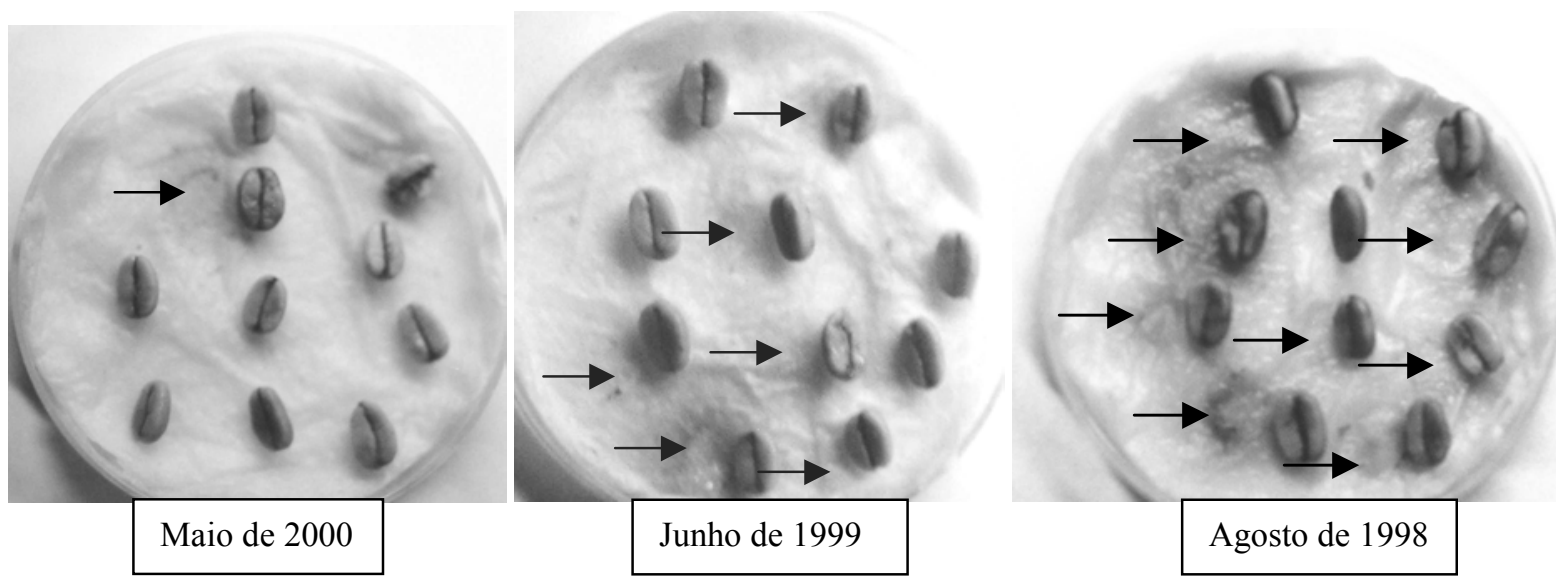

Figura 1. Exsudações marrons, indicadas pelas setas, em sementes de café de maio de 2000, junho de 1999 (câmara fria) e agosto de 1998, avaliadas após 60 horas.

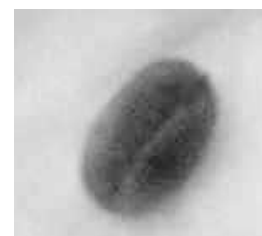

60 hs

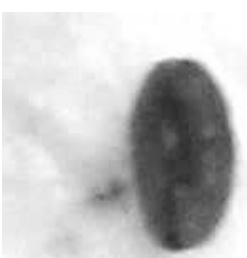

6hs

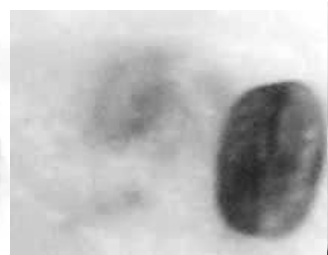

$12 \mathrm{hs}$

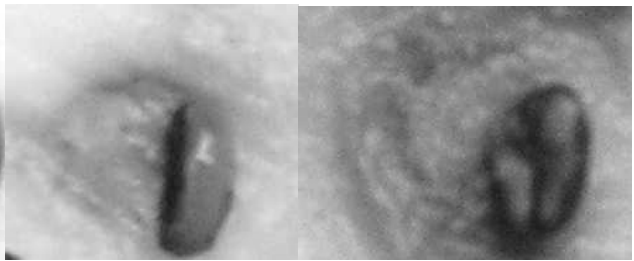

24hs

$60 \mathrm{hs}$

Figura 2. Sementes de café de maio de 2000 e agosto de 1998, apresentando diferentes níveis de exsudação marrom em diferentes períodos de avaliações, após as sementes serem colocadas sobre papel-toalha branco umedecido e fechadas em placas de Petri. As sementes foram levantadas para visualizar melhor as exsudações.

Pelos resultados do vigor germinativo, verificase que houve correlações mais baixas do que o da germinação, porém significativa a $1 \%$.

$\mathrm{O}$ exsudato marrom pode ter ocorrido devido à perda de substâncias lixiviadas no processo de deterioração da semente, ou seja, perda de íons como o potássio, do mesmo modo que Amorim (1978), Prete (1992), Prete et al. (2000a) e Prete, Sera e Fonseca (2000b) observaram em testes de condutividade elétrica em sementes de café defeituosas. Illy et al. (1982) observaram através de microscopia eletrônica que a desorganização celular em grãos de café defeituosos permite que a água penetre e se difunda com maior facilidade nesses grãos.
Neste experimento pode ter ocorrido diminuição da velocidade de germinação pois as avaliações foram realizadas em temperatura média de $17^{\circ} \mathrm{C}$, sendo que o ideal para a germinação é $30^{\circ} \mathrm{C}$ (RENA; MAESTRI, 1986), assim, estas avaliações dos exsudatos poderiam ser até mais rápidas se fossem realizadas em ambiente controlado, com umidade e temperatura altas.

Este método é muito útil, pois entre o envio da semente para teste laboratorial e a recepção do resultado, a análise pode não refletir a real qualidade germinativa no momento da semeadura. Por outro lado, este teste por ser simples e rápido, fornece uma indicação da qualidade germinativa, sem a necessidade de laboratórios. 
Mesmo com precisão menor de $68 \%$ de acerto com apenas 6 horas e $76 \%$ com 12 horas, é possível ter uma indicação para evitar a semeadura de sementes de baixa qualidade. Outros testes rápidos como o teste de tetrazólio (DIAS; SILVA, 1998) e o de condutividade elétrica (SOTO; ECHEVARRIA; RODRIGUEZ, 1995), os quais também são utilizados para avaliar a viabilidade das sementes, necessitam de 40 horas e 8 horas, respectivamente.

Este teste é de grande valor pois não há necessidade de laboratórios, podendo ser utilizado pelos viveiristas e produtores rurais, com baixo custo, sem o uso de mãode-obra especializada como são os casos do teste de tetrazólio e de condutividade elétrica.

\section{Conclusão}

A avaliação da exsudação marrom da semente a partir de 12 horas, dá uma indicação da qualidade germinativa de sementes de café.

\section{Referências}

AMORIM, H. V. Aspectos bioquímicos e histoquímicos do grão de café verde relacionados com a deterioração da qualidade. 1978. Tese (Doutorado em Agrônomia) Escola Superior de Agricultura "Luiz de Queiroz", Piracicaba.

BRASIL. Ministério da Agricultura, do Abastecimento e da Reforma Agrária. Regras para análise de sementes. Brasília, 1992.

DIAS, M. C. L L.; SILVA, W. R. Teste de Tetrazólio em sementes de café. Londrina: IAPAR, 1998. (Boletim Técnico n. 59)
ILLY, E.; BRUMEN, G.; MASTROPASQUA, L.; MAUGHAN, W. Study on the characteristics and the industrial sorting of defective beans in green coffee lots. In: COLOQUIO CIENTÍFICO INTERNACIONAL SOBRE O CAFÉ, 10., 1982, Salvador, 1982. Anais... Salvador: [s.n], 1982.p. 99-128.

MAGAlhÃES, P. C.; DURÃES, F. O. M. Aspectos fisiológicos para o consumo como milho-verde. In: PEREIRA-FILHO, I. A. (Ed.). O cultivo do milho-verde. Brasília: EMBRAPA, 2003.p. 49-66.

MATIELLO, José Braz. Formação do cafeeiro: o café do cultivo ao consumo. São Paulo: Globo, 1991.

PRETE, C. E. C. Condutividade elétrica dos exsudatos de grãos de café (Coffea arabica L.) e sua relação com a qualidade da bebida. 1992. Tese (Doutorado) - Escola Superior de Agricultura “Luiz de Queiroz”, Piracicaba.

PRETE, C. E. C.; SERA, T.; CRUDI, C. E.; FONSECA, I. C. B. Condutividade elétrica de exsudatos de grãos de café colhidos em diferentes estádios de maturação. In: INTERNATIONAL SEMINAR ONBIOTECHNOLOGY IN THE COFFEE AGROINDUSTRY, 3., 1999, Londrina. Proceedings... Londrina: IAPAR/IRD, 2000. p. 475-477.

PRETE, C. E. C.; SERA, T.; FONSECA, I. C. B. Electric conductivity of exudates of green coffee and its relationship with the quality of the beverage. In: SERA, T.; SOCCOL, C. R.; PANDEY, A.; ROUSSOS, S. (Ed.). Coffee biotechnology and quality. Dordrecht : Kluwer Academic Publishers, 2000b. p. $321-338$.

RENA, A. B.; MAESTRI, M. Fisiologia do cafeeiro. In: RENA, A. B.; MALAVOLTA, E.; ROCHA, M. YAMADA, T. (Ed.). Cultura do cafeeiro fatores que afetam a produtividade. Piracicaba: Associação Brasileira para Pesquisa da Potassa e do Fosfato., 1986. p. 16 - 17.

SOTO, F.; ECHEVARRIA, I.; RODRIGUEZ, P. Estudio sobre la conservacion de semillas de cafetos (Coffea Arabica L. variedad Caturra). Cultivos Tropicales, Havana, v.16, n.1, p. 33-36, 1995. 